\title{
Awareness of primary health care physicians about human papilloma virus infection and its vaccination: a cross-sectional survey from multiple clinics in Saudi Arabia
}

This article was published in the following Dove Press journal: Infection and Drug Resistance

\author{
Ebtehaj S Almughais' \\ Ali Alfarhan' \\ Mahmoud Salam² \\ 'Department of Family Medicine and \\ PHC, King Abdullah International \\ Medical Research Center/King Saud \\ Bin Abdulaziz University for Health \\ Sciences, Ministry of National \\ Guard Health Affairs, Riyadh, Saudi \\ Arabia; ${ }^{2}$ Science and Technology \\ Unit, King Abdullah International \\ Medical Research Center/King Saud \\ Bin Abdulaziz University for Health \\ Sciences, Ministry of National Guard \\ Health Affairs, Riyadh, Saudi Arabia
}

Correspondence: Mahmoud Salam Science and Technology Unit, King Abdullah International Medical Research Center/King Saud Bin Abdulaziz University for Health Sciences, 22490 , exit 13, King Abdulaziz Medical City, Riyadh I I426, Saudi Arabia Tel +966534284644 Emailmahmoudsalam@hotmail.com
Background: The incidence of human papilloma virus (HPV) infections in conservative populations is increasing, yet vaccination is not routinely recommended by primary health care (PHC) physicians. The aim of this study is to evaluate PHC physicians' awareness of HPV infections and vaccination in Saudi Arabia.

Materials and methods: A self-administered survey was conducted in 2017 at eleven PHC clinics in Saudi Arabia. Their knowledge on HPV infections (six statements) and HPV vaccines (ten statements), their perceived importance of HPV vaccine, and if they recommended this vaccine to their patients was evaluated. Knowledge scores were summated and commuted into percentage mean scores (PMS). Analyses were conducted to identify factors associated with these outcomes. Results: Almost $80 \%$ of physicians perceived HPV vaccine as necessary and important, while $33(16.5 \%)$ actually recommend HPV vaccine to their patients. Overall PMS \pm standard deviation of knowledge on HPV infections and vaccine was $61.8 \pm 10.4$ and $91.3 \pm 11.4$, respectively. Female physicians had a better perception of the importance of the vaccine $(94 ; 84.7 \%)$, compared to male physicians $(65 ; 73.0 \%), P=0.043$. Younger physicians ( $<38$ years) had better perception of the importance of HPV vaccine $(75 ; 88.2 \%)$, compared to older physicians ( $\geq 38$ years) ( 84 ; $73 \%), P=0.009$. Family medicine physicians were more knowledgeable about both HPV infections $(62.1 \pm 9.7)$ and HPV vaccine $(91.2 \pm 12.0)$, compared to physicians of other specialties (56.3 \pm 13.7 and $85.8 \pm 10.2), P=0.03$ and $P=0.007$, respectively. $P H C$ physicians who routinely recommended HPV vaccine were also more knowledgeable (96.7 \pm 5.4$), P=0.005$. Compared to males, females were 3.1 times more likely to recommend HPV vaccines, adjusted $P=0.015$. Physicians who had better perception of the importance of vaccine were 4.8 times more likely to recommend vaccination, adjusted $P=0.042$.

Conclusion: Enhancing PHC physicians' knowledge about HPV infections and the efficiency of its vaccine boosts the physicians' confidence to recommend HPV vaccination. Special consideration should be paid to male PHC physicians and older physicians, who had poorer perception of the importance of HPV vaccines in comparison to their counter groups.

Keywords: perception, HPV, vaccine, knowledge, conservative

\section{Introduction}

Human papilloma viruses (HPVs) are widely prevalent sexually transmitted pathogens responsible for both anogenital warts and cervical cancers. ${ }^{1}$ HPVs less frequently cause upper genital tract cancers, such as endometrial and ovarian cancer. ${ }^{2}$ There are more than 150 known types of HPV, among which almost 40 strains were confirmed 
to infect the genital areas. ${ }^{3}$ HPV types $(6,11,42$, and 44) are non-oncogenic, while other persistent types (such as 16 , $18,31,33,35,45,51,52,58,59$, and 68 ) are known to be oncogenic. ${ }^{3}$ The PCR detection technique is currently considered the most sensitive HPV diagnostic test. ${ }^{4}$

Cervical cancer is the second leading type of cancer among females aged 15-44 years. ${ }^{5}$ Incidence of HPV infections varies significantly across countries and within communities, often associated with the age factor, risky sexual behavior, and cultural norms. ${ }^{6}$ Since HPVs are only transmitted sexually, it is speculated that their prevalence is low among religiously conservative communities. The Information Center on HPV and Cancer issued a fact sheet in 2017, claiming that there is a lack of data on the HPV burden within the general Saudi Arabian population. One regional study reported that $2.3 \%$ of women in the general population are estimated to harbor high risk HPV16/18 infection at a given time. ${ }^{7}$ Cervical cancer is the eighth most prevalent cancer among Saudi females (2.1 per 100,000), ${ }^{8}$ among whom $92 \%$ are infected with HPV-16 and HPV- $18 .{ }^{9}$ In such communities, the majority of sexually active partners are legally married couples of opposite sex whose marriage has been registered in both religious and/or civil courts. One of the main prerequisites of legally bound marriages in such countries is passing a premarital screening test that identifies sexually transmitted infections and gene carriers of hematologic diseases, such as sickle cell anemia. These regulations have been set to control the spread of sexually transmitted infections including HPVs.

Due to the nature of such conservative communities, authors suspect that the public might perceive HPV as a taboo topic, not to be disclosed to parents, spouses or even primary health care (PHC) physicians. Contracting HPV after marriage is often a label of fornication. Children (11-12 years) may experiment with high risk sexual behaviors, but in conservative communities these teenagers are less likely to admit it to their parents or school nurses. Therefore, it is a great challenge for both PHC physicians and researchers to overcome the underreporting of HPV infections in such communities, and evidence on this matter remains scarce.

A nationwide prevention of high risk HPV demands cytology screening (Pap smear) and vaccination. The bivalent HPV vaccine (HPV2, Cervarix) and quadrivalent HPV vaccine (HPV4, Gardasil) are two types of vaccines that protect against HPV-16 and HPV-18. ${ }^{10}$ Approved by the US Food and Drug Administration (FDA) since 2006, and recommended by the Centers of Diseases Control \& Prevention (CDC) for both genders, HPV vaccine is successful as a primary preven- tion against cervical cancers. ${ }^{11}$ Since 2007, many developed countries have been recommending preventive vaccines against $H P V,{ }^{12}$ to be routinely given at $11-12$ years of age in two doses. Additionally, HPV vaccine has been recommended for females and males who were previously unvaccinated aged 13-26 and 13-21, respectively. ${ }^{10}$ However, the most cost-effective method of preventing HPV transmission is raising awareness within the community and specifically among teenagers; this requires enriching the knowledge of PHC physicians and school nurses. The purpose of this study is to evaluate PHC physicians' knowledge about HPV infections and its vaccine, as well as to assess their perception towards recommending HPV vaccination among a Middle Eastern community.

\section{Materials and methods}

A cross-sectional study was conducted between May and August 2017 at eleven randomly selected PHC facilities distributed across four regions in Saudi Arabia. Four clinics were situated in the capital city Riyadh (Central Region), three clinics in the eastern and western suburbs of the capital, one clinic each in Arar and Hail (Northern Regions), one clinic in Najran (Southern Region), and one clinic in Qassim (North Central Region). The study was approved by the Institutional Review Board of the Saudi Ministry of National Guard Health Affairs (MNG-HA), with a protocol number RC17/063. MNG-HA is the second largest health care sector in the kingdom, second to the Saudi Ministry of Health (MOH). The MNG-HA provides health care services to the community of national guards, their dependents and employees. ${ }^{13}$ In addition, there are over 20 schools of various educational levels affiliated with MNG-HA, and one major university for health sciences that encompasses over eight faculties of various health sciences. A team of 250 PHC physicians work at these clinics that currently serve a population exceeding 180,000 registrants, at a rate of four visits per registrant annually. ${ }^{13}$ The number of Saudi Arabian women in their reproductive age ( $\geq 15$ years) has exceeded 9.8 million, and the WHO has accounted them at risk. ${ }^{14}$ Saudi FDA approved prophylactic HPV vaccine in 2010 for females of age $11-26$ years. ${ }^{15} \mathrm{HPV}$ vaccines are limited to few major hospitals in Saudi Arabia and are offered upon request based on a medical prescription.

Eligible study participants were all certified by the Saudi Commission for Health Specialties and were employed as full time PHC physicians at the targeted setting. A list of email addresses for all 250 PHC physicians employed at the targeted setting was obtained from the head of family medicine 
and PHC department. Convenient sampling technique was used as some PHC physicians might have been on leave, thus cannot access their work emails and participate in this study. An English-language anonymous survey attached with an informed consent was sent by email to these physicians. Study participants consented by ticking an "agreement to participate" statement at the bottom of the consent. Participation was voluntary and confidential as no influence bias or stressors were imposed by the study investigators.

The survey comprised three domains. The physicians' characteristics were mainly sex, age (years), nationality (local vs expatriate), and medical specialty (family medicine [FM] vs other specialties, such as pediatricians and gynecologists). Physicians' attitude towards HPV vaccine was assessed using two straightforward dichotomous questions that clearly asked physicians if they perceived HPV vaccine as important and necessary to the public safety (yes vs no) and if they recommended the vaccine to their patients (routinely vs never/ rarely). The physicians' knowledge about HPV infections (six statements) and HPV vaccine (ten statements) were evaluated against undisputable facts sourced from the Mayoclinic CON20163998. ${ }^{16}$ The inter-rater reliability, Cronbach's alpha, of the tool was 0.73 (Figure S1).

The statistical program SPSS v.25 (IBM Corporation, Armonk, NY, USA) was used for data analysis. Categorical variables such as physicians' characteristics, their responses to perception and knowledge statements were described in frequencies and percentages (n, \%). Individual knowledge statements were scored (correct: 1 vs false and do not know: 0 ), then summated before the percentage mean scores (PMS) were commuted for the two domains: HPV infection and HPV vaccine. PMS of knowledge were presented in mean \pm standard deviation (SD), where higher scores entailed higher levels of knowledge, and vice versa. Normality tests showed that the PMS of both knowledge outcomes were skewed, so Mann-Whitney test $(Z)$ was used to test for statistically significant differences across physicians' characteristics. Pearson's chi-square $\left(\chi^{2}\right)$ was used to determine factors associated with better perception/attitude towards HPV vaccine across sample characteristics. To identify factors associated with the attitude of recommending HPV vaccine, a binary logistic regression model was constructed. Statistical significance was set at $P$-value $<0.05$.

\section{Results}

\section{Physicians' characteristics}

The survey was emailed to all 250 PHC physicians working at the targeted clinics, among whom 230 agreed to
Table I Physicians' characteristics and outcomes

\begin{tabular}{|l|l|}
\hline & $\mathbf{n}(\%)$ \\
\hline $\begin{array}{l}\text { Sex } \\
\text { Male }\end{array}$ & $1 \mathrm{II}(55.5)$ \\
\hline $\begin{array}{l}\text { Age group (years) } \\
<38\end{array}$ & $89(44.5)$ \\
$\geq 38$ & $85(42.5)$ \\
Mean \pm SD & $115(57.5)$ \\
\hline $\begin{array}{l}\text { Nationality } \\
\text { Saudi }\end{array}$ & $38.8 \pm 4.3$ \\
$\quad$ Non-Saudi & $91(45.5)$ \\
\hline Specialty of physician & $109(54.5)$ \\
FM & \\
Others & $142(71.0)$ \\
\hline Perceived importance of HPV vaccine & $58(29.0)$ \\
Necessary & $159(79.5)$ \\
Not necessary & $4 I(20.5)$ \\
\hline Recommendation of HPV vaccine & \\
Routinely & $33(16.5)$ \\
Never/rarely & $167(83.5)$ \\
\hline
\end{tabular}

Abbreviations: FM, family medicine; HPV, human papilloma virus; SD, standard deviation.

participate, and 200 (87\%) fully completed all the knowledge statements in the survey. The male-to-female ratio was $1: 1.24$. The mean \pm SD of participants' age was $38.8 \pm 4.3$ years, among whom $115(57.5 \%)$ of participants were $\geq 38$ years old. Saudi physicians (locals) comprised 91 (45.5\%) of the sample, in comparison to 109 expatriate non-Saudi physicians (54.5\%). FM physicians comprised 142 (71\%) of the sample, while $58(29 \%)$ were of other specialties. Almost $80 \%$ of study participants perceived HPV vaccine as necessary and important to public safety, while only $33(16.5 \%)$ actually recommend the HPV vaccine to their patients (Table 1).

\section{Physicians knowledge on HPV infection and vaccine}

Correct responses to individual knowledge statements are ranked by order in Table 2 . All physicians correctly acknowledged the fact that HPV is detected by Pap smear, PCR and biopsy, and that HPV vaccine can be administered through intramuscular injections. The majority $(183 ; 91.5 \%)$ correctly confirmed that HPV types 16 and 18 are associated with an elevated risk of cervical cancers, and that HPV vaccination provides protection against carcinomas of cervix and genital warts $(196 ; 98 \%)$. Other knowledge statements are listed in Table 2. The overall PMS \pm SD of knowledge on HPV infections was $61.8 \pm 10.4$, while the $\mathrm{PMS} \pm \mathrm{SD}$ of knowledge on HPV vaccine was 91.3 \pm 11.4 . 
Table 2 Physicians' knowledge about HPV infections and HPV vaccine

\begin{tabular}{|c|c|c|}
\hline \multicolumn{2}{|c|}{ Knowledge about HPV infections } & \multirow{2}{*}{\begin{tabular}{|l|} 
Correct response, $\mathbf{n}(\%)$ \\
$200(100)$ \\
\end{tabular}} \\
\hline $\mathrm{I}$ & The techniques available for HPV detection are pap smear, PCR and biopsy & \\
\hline 2 & HPV types 16 and I8 are associated with high risk of cervical cancer & $183(9 \mid .5)$ \\
\hline 3 & HPV is the most common sexually transmitted infection (STI) & $179(89.5)$ \\
\hline 4 & Low-risk HPV types 6 and II cause $90-95 \%$ of genital warts & $173(86.5)$ \\
\hline 5 & Persistent HPV infection necessarily causes cervical cancer & $158(79.0)$ \\
\hline 6 & HPV can be detected by a blood test & $27(13.5)$ \\
\hline \multicolumn{2}{|c|}{$\begin{array}{l}\text { Percentage mean score } \pm \text { SD } \\
\text { Median [IQR] }\end{array}$} & $\begin{array}{l}61.8 \pm 10.4 \\
66.7[16.7]\end{array}$ \\
\hline \multicolumn{3}{|c|}{ Knowledge about HPV vaccine } \\
\hline I & HPV vaccine is administered through intramuscular injections & $200(100)$ \\
\hline 2 & HPV vaccination provides protection against cervical carcinoma and genital warts & $196(98.0)$ \\
\hline 3 & Vaccination is not a substitute for cervical cancer screening & $194(97.0)$ \\
\hline 4 & HPV vaccine is recommended for young females ( $<26$ years) and males $(<2 I$ years) & $191(95.5)$ \\
\hline 5 & The second dose of HPV should be given 6-12 months after the first dose & $187(93.5)$ \\
\hline 6 & Two doses of vaccine should be given & $186(93.0)$ \\
\hline 7 & HPV vaccine may be given to both males and females & $181(90.5)$ \\
\hline 8 & HPV vaccine can be administered at $\mathrm{II}-12$ years of age & $173(86.5)$ \\
\hline 9 & HPV vaccination is contraindicated in pregnancy & $169(84.5)$ \\
\hline 10 & HPV vaccine has an efficacy of $>90 \%$ & $124(62.0)$ \\
\hline \multicolumn{2}{|c|}{$\begin{array}{l}\text { Percentage mean score } \pm \text { SD } \\
\text { Median [IQR] }\end{array}$} & $\begin{array}{l}91.3 \pm 11.4 \\
100[20] \\
\end{array}$ \\
\hline \multicolumn{2}{|c|}{$\begin{array}{l}\text { Total knowledge percentage mean score } \pm \text { SD } \\
\text { Median [IQR] }\end{array}$} & \begin{tabular}{|l|}
$79.8 \pm 9.9$ \\
$81.3[12.5]$
\end{tabular} \\
\hline
\end{tabular}

Abbreviations: HPV, human papilloma virus; SD, standard deviation; IQR, interquartile range.

Table 3 General perception of physicians about HPV vaccine across their characteristics

\begin{tabular}{|c|c|c|c|c|}
\hline & \multicolumn{2}{|c|}{ Perceived importance of HPV vaccine } & \multicolumn{2}{|c|}{ Recommendation of HPV vaccine } \\
\hline & Necessary (\%) & Not necessary (\%) & Routinely (\%) & Never/rarely (\%) \\
\hline \multicolumn{5}{|l|}{ Sex } \\
\hline Female & $94(84.7)$ & $17(15.3)$ & $25(22.5)$ & $86(77.5)$ \\
\hline \multirow[t]{2}{*}{ Male } & $65(73.0)$ & $24(27.0)$ & $8(9.0)$ & $81(91.0)$ \\
\hline & \multicolumn{2}{|l|}{$\chi^{2}=1.114, P=0.043^{*}$} & \multicolumn{2}{|c|}{$\chi^{2}=6.567, P=0.010^{*}$} \\
\hline \multicolumn{5}{|l|}{ Age group (years) } \\
\hline$<38$ & $75(88.2)$ & $10(11.8)$ & $12(14.1)$ & $73(85.9)$ \\
\hline \multirow[t]{2}{*}{$\geq 38$} & $84(73.0)$ & $31(27.0)$ & $21(18.3)$ & $94(81.7)$ \\
\hline & \multicolumn{2}{|l|}{$\chi^{2}=6.921, P=0.009 *$} & \multicolumn{2}{|c|}{$\chi^{2}=0.609, P=0.435$} \\
\hline \multicolumn{5}{|l|}{ Specialty of physician } \\
\hline FM & III (78.2) & $31(21.8)$ & $24(16.9)$ & $118(83.1)$ \\
\hline \multirow[t]{2}{*}{ Other } & $48(82.8)$ & $10(17.2)$ & $9(I 5.5)$ & $49(84.5)$ \\
\hline & \multicolumn{2}{|l|}{$\chi^{2}=0.532, P=0.466$} & \multicolumn{2}{|c|}{$\chi^{2}=0.057, P=0.8 \mathrm{II}$} \\
\hline
\end{tabular}

Note: *Statistically significant at $<0.05$.

Abbreviations: $\chi^{2}$, Pearson's chi-square; FM, family medicine; HPV, human papilloma virus.

\section{Factors associated with study outcomes}

Female PHC physicians had better perception about the importance of HPV vaccine as a necessary precaution to public safety ( $94 ; 84.7 \%$ ), compared to male physicians ( 65 ; $73.0 \%$ ). Females were also more likely to recommend HPV vaccine to their patients $(25 ; 22.5 \%)$, compared to males $(8$; $9.0 \%), P=0.01$. In addition, younger physicians were more likely to view HPV vaccine as a necessary public safety issue $(75 ; 88.2 \%)$, compared to older physicians $(84 ; 73 \%)$, $P=0.009$ (Table 3).
FM physicians had higher knowledge scores on both HPV infections (62.1 \pm 9.7$)$ and HPV vaccine (91.2 \pm 12.0$)$, compared to physicians of other specialties $(56.3 \pm 13.7)$ and (85.8 \pm 10.2$), P=0.03$ and $P=0.007$, respectively. PHC physicians who routinely recommended HPV vaccine to their patients had higher knowledge scores $(96.7 \pm 5.4)$, compared to their counter group who never or rarely recommended it (90.2 \pm 11.9$), P=0.005$ (Table 4). Compared to male PHC physicians, females were 3.1 times more likely to recommend HPV vaccines to their patients, adjusted $P=0.015$. PHC 
Table 4 Knowledge scores across physician and outcome characteristics

\begin{tabular}{|l|l|l|}
\hline & $\begin{array}{l}\text { Knowledge about HPV infections } \\
\text { PMS } \pm \text { SD }\end{array}$ & $\begin{array}{l}\text { Knowledge about HPV vaccine } \\
\text { PMS } \pm \text { SD }\end{array}$ \\
\hline $\begin{array}{l}\text { Sex } \\
\text { Female }\end{array}$ & $61.4 \pm 10.5$ & $92.4 \pm 10.3$ \\
Male & $62.3 \pm 10.1$ & $89.9 \pm 12.5$ \\
\hline & $Z=-0.66, P=0.509$ & $Z=-1.07, P=0.284$ \\
\hline $\begin{array}{l}\text { Age group (years) } \\
<38\end{array}$ & $61.2 \pm 10.4$ & \\
$\geq 38$ & $62.2 \pm 10.3$ & $91.7 \pm 10.6$ \\
\hline & $Z=-0.71, P=0.479$ & $90.9 \pm 11.9$ \\
\hline $\begin{array}{l}\text { Specialty of physician } \\
\text { FM }\end{array}$ & $62.1 \pm 9.7$ & $Z=-0.06, P=0.952$ \\
Other & $56.3 \pm 13.7$ & \\
\hline & $Z=-2.13, P=0.033^{*}$ & $91.2 \pm 12.0$ \\
\hline Perceived importance of HPV vaccine & $61.6 \pm 10.1$ & $Z=-2.71, P=0.007^{*}$ \\
\hline Necessary & $62.6 \pm 11.4$ & \\
Not necessary & $Z=-0.38, P=0.698$ & $91.9 \pm 11.0$ \\
\hline & & $88.7 \pm 12.6$ \\
\hline Recommendation of HPV vaccine to patients & $64.1 \pm 7.4$ & $Z=-1.50, P=0.134$ \\
Routinely & $61.3 \pm 10.8$ & $96.7 \pm 5.4$ \\
Never/rarely & $Z=0.14, P=0.135$ & $90.2 \pm I I .9$ \\
\hline & & $Z=-2.79, P=0.005^{*}$ \\
\hline
\end{tabular}

Note: *Statistically significant at $<0.05$.

Abbreviations: FM, family medicine; HPV, human papilloma virus; PMS, percentage mean score; Z, Mann-Whitney test Z-score.

Table 5 Factors associated with the physicians' recommendation of the HPV vaccine

\begin{tabular}{|l|l|l|l|}
\hline & B (SE) & Adj. P-value & Adj. OR [95\% CI] \\
\hline $\begin{array}{l}\text { Sex } \\
\text { Male=0; female=1 }\end{array}$ & $1.12(0.46)$ & $0.015^{*}$ & $3.1[1.2-7.5]$ \\
\hline $\begin{array}{l}\text { Age group (years) } \\
\geq 38=0 ;<38=1\end{array}$ & $-0.48(0.45)$ & 0.285 & $0.6[0.3-1.5]$ \\
\hline $\begin{array}{l}\text { Specialty of physician } \\
\text { FM=0; other =I }\end{array}$ & $-0.39(0.45)$ & 0.379 & $0.7[0.3-1.6]$ \\
\hline $\begin{array}{l}\text { Perceived importance of HPV vaccine } \\
\text { Not necessary=0; necessary=I }\end{array}$ & $1.55(0.76)$ & $0.042^{*}$ & $4.8[1.1-21.3]$ \\
\hline
\end{tabular}

Note: *Statistically significant at $<0.05$.

Abbreviations: 0, reference group; I, compared group; Adj., adjusted; B, beta coefficient of determination; FM, family medicine; HPV, human papilloma virus; OR, odds ratio; $\mathrm{Cl}$, confidence interval.

physicians who acknowledged HPV vaccine as a necessary public safety issue were 4.8 times more likely to recommend it to patients in comparison to their counter group, adjusted $P=0.042$ (Table 5).

\section{Discussion}

The authors of this study believe that knowledgeable PHC physicians are a great asset to any health care institution, and that they are crucial in the fight against both communicable and noncommunicable diseases around the world. Regarding HPV, their primary goal is to provide preventive or precautionary health care services by spreading awareness and recommending either screening and/or HPV vaccination. The present authors see PHC physicians as disseminators of HPV related knowledge and its vaccine in both clinics and academic settings (schools and universities). The relationship between physicians' level of knowledge and the public's compliance with disease control/prevention has been investigated in a few studies, but none were HPV related. One community based study in Saudi Arabia reported that only 101 (32.2\%) of women were aware of HPV and 285 (89.9\%) expressed an interest in vaccination. ${ }^{17} \mathrm{~A}$ survey among young men visiting a dermatology clinic showed that there was a high level of HPV vaccine acceptance (83\%), claiming that barriers to vaccination were mainly the cost and potential side effects, while a physician's recommendation was the main facilitator. ${ }^{18}$ Trust, knowledge, regard, and loyalty are four main elements in a physician-patient relationship. ${ }^{19}$ For instance, the Guidance-Cooperation Model entails that the physician is placed in a position of power due to having the 
medical knowledge that the patient lacks on HPV infections. ${ }^{19}$ Moreover, the emergence of the Internet has given the public a wealth of information on sexually transmitted diseases such as HPV. ${ }^{20}$ Therefore, PHC physicians are expected to decide what is in the patient's best interest and to make recommendations accordingly. ${ }^{19}$

Few studies have evaluated the knowledge of PHC physicians on HPV infections and vaccines in relatively conservative Middle Eastern communities. Populations in this region consist of diverse ethnic, linguistic, sectarian, familial, tribal, religious, socioeconomic, and national identities, though Western cultural norms have been disseminated into the Middle Eastern communities. ${ }^{21}$ The present authors presume that since HPV is a sexually transmitted disease, disclosing such topics between a PHC physician and patients in these communities requires a sensitive approach. When PHC physicians discuss such topics with their patients, especially in the presence of a companion, social desirability bias might arise. This is mainly due to the fact that these patients are under pressure imposed by their conservative culture which leads to an underreporting of risky sexual activities or even denial from the patient/family side if the disease is confirmed. Physicians' knowledge on HPV in Saudi Arabia as an Asian country was compared to studies in India, Thailand and Hong Kong in Far East Asia, to Turkey, a proximal country to both Arabian Middle East and Europe, and to Kuwait, a neighboring country, all summarized in Table 6. Compared to the neighboring Arabian Gulf settings, physicians in this study had almost similar levels of knowledge, ${ }^{22,23}$ which is a reflection of comparable study populations. However, figures reported by two far east Asian settings ${ }^{24,25}$ and one Indian setting ${ }^{26}$ were much lower, which can be attributed to their health sector's lack of interest or low priority towards HPV public awareness campaigns and medical education. PHC physicians in Saudi Arabia might exhibit lower knowledge scores in comparison to other Asian settings ${ }^{27-29}$ probably due to their lower sense of urgency about HPV infections or vaccines, given the conservative population they serve. It is hypothesized that PHC physicians might miss out on opportunities to advise their patients about HPV due to their lack of knowledge or educational skills. Even though the level of knowledge in this setting was slightly higher than what was reported in other settings, yet physicians are expected, as perceived by their community, to be fully aware of any health care aspect including HPV. Therefore, the study investigators suggest that improving the PHC physicians' knowledge on both HPV infection and its vaccine is a main goal for any health care facility.

HPV vaccine has been largely perceived as a precautionary measure against cervical cancers in women, though indication for its use in men is expanding to prevent genital warts and anal cancers. ${ }^{30}$ Gender differences were observed in this study regarding the perceived importance of HPV vaccine and recommending it to the public. In one study, both male and female physicians were observed to be interested in recommending the HPV vaccine. ${ }^{31}$ However, in this setting there was better perception among female PHC physicians. Although not assessed in this setting, the authors suspect that a limited disclosure of high risk sexual behavior between both male/female patients and PHC physicians of opposite gender might exist, given the conservative nature of this community and the sensitivity of discussing sexually transmitted diseases. Another speculation would be that since male PHC physicians mainly examined male patients at this setting, they might have falsely perceived that HPV only affects women, rather than the fact that HPV positive male patients are also at high risk of penile and anal cancers. Less frequently recommending HPV vaccine among male physicians could have weakened their personal knowledge on HPV with time, which was evident in their poorer knowledge scores compared

Table 6 Brief summary of studies that evaluated the physicians' knowledge on HPV infections and/or HPV vaccines in Asia

\begin{tabular}{|c|c|c|c|c|}
\hline Author surname, published year & Sample size & Country & Aspect of knowledge & $\begin{array}{l}\text { Comparison to the level of } \\
\text { knowledge in this setting }\end{array}$ \\
\hline Aljuwaihel et al, $2013^{22}$ & 125 & Kuwait & HPV infection & Slightly higher \\
\hline Sait, 20I I ${ }^{23}$ & 200 & Saudi Arabia & HPV infection & Slightly higher \\
\hline Songthap et al, $2009^{24}$ & 100 & Thailand & $\begin{array}{l}\text { HPV infection } \\
\text { HPV vaccine }\end{array}$ & $\begin{array}{l}\text { Lower level } \\
\text { Lower level }\end{array}$ \\
\hline Wong et al, $2013^{25}$ & 444 & Hong Kong & HPV infection & Lower level \\
\hline Canon et al, $2017^{26}$ & 210 & India & HPV vaccine & Lower level \\
\hline Ozsurekci et al, $2013^{27}$ & 226 & Turkey & $\begin{array}{l}\text { HPV infection } \\
\text { HPV vaccine } \\
\end{array}$ & $\begin{array}{l}\text { Higher level } \\
\text { Lower level }\end{array}$ \\
\hline Naki et al, $2010^{28}$ & 142 & Turkey & HPV infection & Higher level \\
\hline Swapnajaswanth et al, $2014^{29}$ & 57 & India & $\begin{array}{l}\text { HPV infection } \\
\text { HPV vaccine }\end{array}$ & $\begin{array}{l}\text { Higher level } \\
\text { Higher level }\end{array}$ \\
\hline
\end{tabular}


to female physicians. However, these speculations require further investigation.

FM physicians had higher knowledge scores compared to their counter group, such as pediatricians and gynecologists. The authors of the present study believe that FM physicians are in broader contact with the public community, whereas others examine patients upon medical referrals. Therefore, it is imperative that the FM group be more knowledgeable. Younger physicians had better perception of the importance of HPV vaccines than older physicians. This might indicate that younger physicians were better informed on the increasing incidences of HPV globally and locally. Higher levels of knowledge were significantly associated with higher rates of physicians recommending the HPV vaccine. This indicates that the personal confidence of PHC physicians is increased by enhancing their knowledge which will in return improve their attitude towards recommending HPV screening and vaccination. It is noteworthy that $\mathrm{PHC}$ physicians might be involuntarily overwhelmed with their work due to time constraints and a hectic schedule. Therefore, communication and interaction is vital between the PHC physicians and their patients.

The study investigators suggest that advising the public community about the HPV risk factors, screening and vaccination all remain the simplest and most cost-effective PHC method of disease prevention. Recently, the cost of treatment has become an important issue in the health care sector. ${ }^{32}$ Although cost-effectiveness criteria differ between countries of various economic levels, it was unjustifiable to establish either screening or vaccination programs if Saudi Arabia has a low rate of high risk HPV in both genders. ${ }^{33}$ In other words, launching a Saudi national vaccination program may not logically reduce these rates of HPV induced cancers, because it is already very low. ${ }^{33}$ For instance, if all Saudi teenagers of age 10-14 years are scheduled for vaccination (three shots), it would be a costly burden on the health sector, in comparison to other health care priorities, as the cost of HPV vaccines ranges from $\$ 130$ to $\$ 170$ per shot. ${ }^{33}$ Accordingly, screening or vaccination offers only selected individuals who are confirmed at high risk of HPV infection, or those who were informed about the risk, or those who voluntarily wanting to be vaccinated. ${ }^{9}$ The present authors reiterate that patients view their PHC physicians as influential advisors. Consultation and advice from physicians increases public awareness of HPV infections and vaccine, thus triggering public willingness to screen for HPV and cervical cancers. Therefore, advice (based on good knowledge) is more informal and cost-effective than other community launched vaccination campaigns.

There are some limitations to this study. Although the recruitment of study participants was conducted in multiple PHC clinics, the relatively small sample size might limit its statistical power and generalizability to other settings. However, the study was conducted in a population with distinctive characteristics. Variations in physician characteristics across other regions are expected to be low, so results in this study can be generalized to other settings where relatively conservative communities reside. Some physician characteristics might influence their knowledge on and perception of HPV infections and vaccines, such as years of experience and previous contact with HPV positive cases that were overlooked in this study. However, the age of physicians and their years of experience are known to be collinear variables. A certain degree of Hawthorne effect is always expected in such studies, as physicians are expected to be fully aware of any health care issue raised during/across their consultations. Therefore, all study participants were reassured that their responses will be gathered anonymously.

\section{Conclusion}

A knowledgeable PHC physician is a great asset for both the health care institution and the public community. PHC physicians in this setting had relatively good knowledge about HPV infections and its vaccine, yet were in need of further education. Special consideration should be paid to male PHC physicians and older age groups who had poorer perception of the importance of HPV vaccines in comparison to their counter groups. FM physicians appear to be more knowledgeable and competent about this issue. Boosting the knowledge of PHC physicians about HPV infections and its vaccines was effective in enhancing the PHC physicians' confidence to recommend HPV vaccination.

\section{Recommendations}

The vision of any PHC clinic should be to focus, sharpen, and orient their services to meet the demands of their community. The incidence of HPV is increasing globally and health care bills pertinent to cervical cancers are expected to increase as well. Therefore, spreading awareness about HPV precautionary measures is the responsibility of PHC. Parental contribution is a significant factor since the current standards recommend vaccinating children from the age of 9 up to 26 years. Hence, providing education to families on the purpose of vaccines is crucial to bringing together public health and 
safety with the cultural norms in the community. Scheduled educational offerings ensure all physicians are updated with the latest findings on HPV infections. Communication skills can only be refined by the physicians' personal engagement and interaction with their visiting patients.

\section{Key points}

1. HPV infection is sexually transmitted and a leading cause of cervical cancers.

2. Although its incidence in conservative populations is increasing, vaccination is not routinely recommended by PHC physicians.

3. A knowledgeable PHC physician is a great asset for both the health care institution and the public community.

4. Special consideration should be paid to male PHC physicians and older physicians who had poorer perception on the importance of HPV vaccines.

5. Enhancing the knowledge of PHC physicians about HPV infections and its vaccines is effective in boosting the PHC physicians' confidence to recommend HPV vaccination.

\section{List of abbreviations}

HPV, human papilloma virus

PHC, primary health care

PMS, percentage mean scores

FM, family medicine

FDA, Food and Drug Administration

CDC, Centers of Diseases Control \& Prevention

MNG-HA, Ministry of National Guard Health Affairs

$\mathrm{MOH}$, Ministry of Health

\section{Ethics approval and consent to participate}

A self-explanatory letter of invitation to participate was presented electronically to each of the participants. All participants had given informed consent for their participation in the research presented in this manuscript with full knowledge of the possible risks and benefits of participation. Participants consented by ticking "agree," indicating their agreement to provide their feedback for this research study. The study was approved by the Institutional Review Board of the Saudi Ministry of National Guard Health Affairs, Riyadh, Saudi Arabia (Protocol \# RC 17/063). This study followed the recommendations of the International Conference on Harmonization for Good Clinical Practice (ICH-GCP) and the Uniform Requirements for Manuscripts Submitted to Biomedical Journals.

\section{Availability of data and material}

The datasets used and/or analyzed during the current study are available from the corresponding author on reasonable request.

\section{Acknowledgments}

This study was approved and monitored by King Abdullah International Medical Research Center, King Saud bin Abdulaziz University for Health Sciences, Riyadh, Saudi Arabia. Special thanks to the research coordinator Mrs Lara Afesh, to the Research Office and to the Institutional Review Board for their tremendous support. This research did not receive any specific grant from funding agencies in the public, commercial, or not-for-profit sectors.

\section{Author contributions}

All authors conceptualized and designed the study. ESA and AA supervised the conduct of the study and data collection. ESA undertook the recruitment of subjects and managed the data. MS was accounted for the quality control, provided statistical advice on study design, and data analysis. All authors drafted the manuscript, contributed substantially to its revision as submitted, gave final approval of the version to be published, and agreed to be accountable for all aspects of the work.

\section{Disclosure}

The authors report no conflicts of interest in this work.

\section{References}

1. World Health Organization (WHO) Fact Sheet [homepage on the Internet]. Human papillomavirus (HPV) and cervical cancer. June 2016. Available from: http://www.who.int/mediacentre/factsheets/fs380/en/. Accessed May 15, 2018.

2. Wu QJ, Guo M, Lu ZM, Li T, Qiao HZ, Ke Y. Detection of human papillomavirus-16 in ovarian malignancy. Br J Cancer. 2003;89(4):672-675.

3. Rouzier R, Uzan C, Collinet P. Vaccination HPV : principes, résultats et perspectives [HPV vaccination: principles, results and future perspectives]. J Gynecol Obstet Biol Reprod (Paris). 2007;36(1):13-18. French.

4. Harwood CA, Spink PJ, Surentheran T, et al. Degenerate and nested PCR: a highly sensitive and specific method for detection of human papillomavirus infection in cutaneous warts. $J$ Clin Microbiol. 1999;37(11):3545-3555.

5. WHO. Human Papillomavirus and Related ses Report in the world. Summary report. Burden of HPV related Cancer. December 2016. Available from: http://www.hpvcentre.net/statistics/reports/XWX.pdf. Accessed March 10, 2018.

6. Turki R, Sait K, Anfinan N, Sohrab SS, Abuzenadah AM. Prevalence of human papillomavirus in women from Saudi Arabia. Asian Pac $J$ Cancer Prev. 2013;14(5):3177-3181.

7. ICO/IARC Information Centre on HPV and Cancer. Saudi Arabia Human Papillomavirus and Related Cancers, Fact Sheet 2017. Available from: http://www.hpvcentre.net/statistics/reports/SAU_FS.pdf. Accessed April 17, 2018. 
8. Saudi Cancer Registry. Saudi Arabia Cancer Incidence Report 2010. Riyadh, Saudi Arabia: Saudi Cancer Registry, 2014.

9. Alsbeih G. HPV infection in cervical and other cancers in Saudi Arabia: implication for prevention and vaccination. Front Oncol. 2014;4:65.

10. Centers for Disease Control and Prevention (CDC). Updated HPV vaccination Recommendations of the Advisory Committee on Immunization Practices MMWR October 19, 2016. Available from: https://www.cdc. gov/vaccines/acip/meetings/downloads/min-archive/min-2016-10.pdf. Accessed May 20, 2018.

11. CDC [homepage on the Internet]. Sexually transmitted diseases: HPV vaccine information for young women. October 2007. Available from: https://www.cdc.gov/hpv/. Accesed May 29, 2018.

12. Jach R, Basta A, Kotarski J, et al. Ten years of anti-HPV vaccinations: what do we know? Prz Menopauzalny. 2016;15(3):170-175.

13. AlAteeq M, Alrashoud AM, Khair M, Salam M. Smoking cessation advice: the self-reported attitudes and practice of primary health care physicians in a military community, central Saudi Arabia. Patient Prefer Adherence. 2016;10:651-658.

14. Bruni L, Barrionuevo-Rosas L, Albero G, et al. ICO/IARC Information Centre on HPV and Cancer (HPV Information Centre). Human Papillomavirus and Related Diseases in Saudi Arabia. Summary Report. 2017;27.

15. Hussain AN, Alkhenizan A, McWalter P, et al. Attitudes and perceptions towards HPV vaccination among young women in Saudi Arabia. J Family Community Med. 2016;23(3):145-150.

16. MayoClinic. HPV infection. June 2016. Available from: https://www. mayoclinic.org/diseases-conditions/hpv-infection/symptoms-causes/ syc-20351596. Accessed October 14, 2018.

17. AlObaid A, Al-Badawi IA, Al-Kadri H, et al. Human papillomavirus prevalence and type distribution among women attending routine gynecological examinations in Saudi Arabia. BMC Infect Dis. 2014;14:643.

18. Belani HK, Sekar P, Guhaniyogi R, Abraham A, Bohjanen PR, Bohjanen $\mathrm{K}$. Human papillomavirus vaccine acceptance among young men in Bangalore, India. Int J Dermatol. 2014;53(11):e486-e491.

19. Chipidza FE, Wallwork RS, Stern TA. Impact of the doctor-patient relationship. Prim Care Companion CNS Disord. 2015;17(5).

20. Truog RD. Patients and doctors - evolution of a relationship. $N$ Engl $J$ Med. 2012;366(7):581-585.

21. al-Krenawi A, Graham JR. Culturally sensitive social work practice with Arab clients in mental health settings. Health Soc Work. 2000;25(1):9-22.
22. Aljuwaihel A, Al-Jarallah A, Al-Busairi H, El-Shazly MK. Awareness of HPV and Cervical Cancer Vaccine among PHC Physicians in Kuwait. Greener Journal of Medical Sciences. 2013;3(4):152-159.

23. Sait KH. Knowledge, attitudes, and practices regarding cervical cancer screening among physicians in the Western Region of Saudi Arabia. Saudi Med J. 2011;32(11):1155-1160.

24. Songthap A, Pitisuttithum P, Kaewkungwal J, Fungladda W, Bussaratid $\mathrm{V}$, Koonsaeng S. Knowledge, attitudes, and acceptability of a human papillomavirus vaccine among healthcare providers. Southeast Asian J Trop Med Public Health. 2009;40(5):1048-1056.

25. Wong MC, Lee A, Ngai KL, Chor JC, Chan PK. Knowledge, attitude, practice and barriers on vaccination against human papillomavirus infection: a cross-sectional study among primary care physicians in Hong Kong. PLoS One. 2013;8(8):e71827.

26. Canon C, Effoe V, Shetty V, Shetty AK. Knowledge and attitudes towards human papillomavirus (HPV) among academic and community physicians in Mangalore, India. J Cancer Educ. 2017;32(2):382-391.

27. Ozsurekci Y, Karadag Oncel E, Bayhan C, et al. Knowledge and attitudes about human papillomaviruses and immunization among Turkish pediatricians. Asian Pac J Cancer Prev. 2013;14(12):7325-7329.

28. Naki MM, Celik H, Api O, Toprak S, Ozerden E, Unal O. Awareness, knowledge and attitudes related to HPV infection and vaccine among non-obstetrician-gynecologist healthcare providers. JTurk Ger Gynecol Assoc. 2010;11(1):16-21.

29. Swapnajaswanth M, Suman G, Suryanarayana SP, Murthy NS. Perception and practices on screening and vaccination for carcinoma cervix among female healthcare professional in tertiary care hospitals in Bangalore, India. Asian Pac J Cancer Prev. 2014;15(15):6095-6098.

30. Mendoza N, Hernandez PO, Tyring SK. HPV vaccine update: new indications and controversies. Skin Therapy Lett. 2011;16(8):1-3.

31. Alzahrani AA, AlGhanaim N, Abdulmageed S. Perception of the Saudi Community towards Human Papilloma Virus Vaccination in Jeddah, Saudi Arabia. Glob J Health Sci. 2017;9(8):158.

32. Tilburt JC, Wynia MK, Sheeler RD, et al. Views of US physicians about controlling health care costs. JAMA. 2013;310(4):380-388.

33. CDC. Human Papillomavirus (HPV). Questions and Answers. 2016. Available from: http://www.immunize.org/catg.d/p4207.pdf. Accessed May 20, 2018 


\section{Supplementary material}

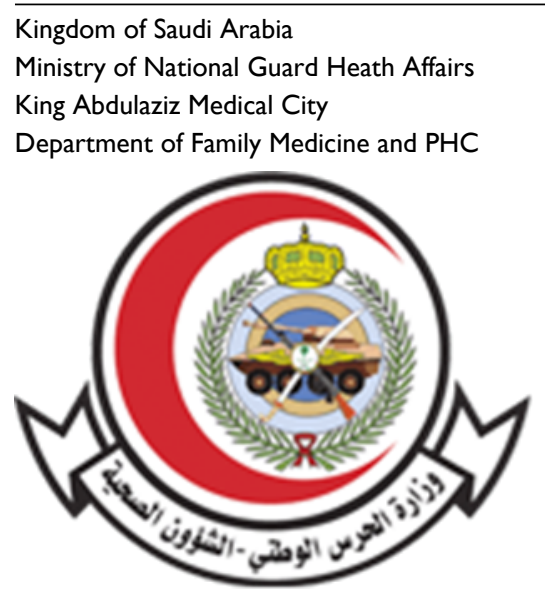

Awareness of primary health care physicians on Human Papilloma Viruses infection and its vaccination: a cross-sectional survey from multiple clinics in Saudi Arabia

Dear Doctor,

As part of my partial fulfillment for registering at the Saudi Board of Family Medicine, I would like to invite you to participate in a quick survey about Human Papilloma Virus infections and its vaccination.

The survey is designed for research purposes only, thus no personal identifiers are required and your feedback will be dealt with utmost confidentiality.

For further details please contact us at: almughaiseb@ngha.med.sa

Best Regards

1- Gender:

- Male

- Female

2- Nationality:

- Saudi

- Other.

3-Age:

-

4- Clinical specialty:

- Family Medicine

- Pediatrician

- Gynecologist

- Other.

5-Location of clinic:

- King Abdulaziz Medical City (Iskan Clinics)

- King Saud City (Dirab PHC)

- NGCSC(UM ALHAMMAM)

- HCSC(KHASHMALAAN)

- KKMAH

- EMPLOYEE HEALTH CLINIC (EMH) 
- RAFHA

- QASSIM

- HAIL

- NAJRAN

- ARAR

6- Do you believe that HPV vaccine is important and necessary to the public safety?

- Yes

- No

7- How often do you recommend HPV vaccine to your patients?

- Routinely

- Rarely

- Never

\section{Human Papilloma Virus infection}

\begin{tabular}{|c|c|c|c|}
\hline & Yes & No & Don't Know \\
\hline \multicolumn{4}{|c|}{ The techniques available for HPV detection are Pap smear, PCR and biopsy } \\
\hline \multicolumn{4}{|c|}{ HPV type 16 and 18 are associated with high risk of cervical cancer } \\
\hline \multicolumn{4}{|c|}{ HPV is the most common sexually transmitted infection (STI) } \\
\hline \multicolumn{4}{|c|}{ Low-risk HPV types 6 and II cause $90 \%$ to $95 \%$ of genital warts } \\
\hline \multicolumn{4}{|c|}{ Persistent HPV infection necessarily causes cervical cancer } \\
\hline HPV can be detected by a blood test & & & \\
\hline
\end{tabular}

\section{Human Papilloma Virus vaccination}

\begin{tabular}{|l|l|l|}
\hline & Yes & Don't Know \\
\hline HPV vaccine is administered through intramuscular injections & & \\
\hline HPV vaccination provides protection against cervical carcinoma and genital warts & & \\
\hline Vaccination is not a substitute for cervical cancer screening & & \\
\hline HPV vaccine is recommended for young females (<26 years) and young males (<2I years) & & \\
\hline The 2nd dose of HPV should be given 6-I2 months after the first dose & & \\
\hline Two doses of vaccine should be given & & \\
\hline HPV vaccine may be given to both males and females & & \\
\hline HPV vaccine can be administered at II-I2 years of age & & \\
\hline HPV vaccination is contraindicated in pregnancy & & \\
\hline HPV vaccine has an efficacy of $>90 \%$ & & \\
\hline
\end{tabular}

Thank you for your valuable participation

Figure SI Study questionnaire. access journal that focuses on the optimal treatment of infection (bacterial, fungal and viral) and the development and institution of preventive strategies to minimize the development and spread of resistance. The journal is specifically concerned with the epidemiology of antibiotic

resistance and the mechanisms of resistance development and diffusion in both hospitals and the community. The manuscript management system is completely online and includes a very quick and fair peerreview system, which is all easy to use. Visit http://www.dovepress.com/ estimonials.php to read real quotes from published authors. 